\title{
Synchronous Renal Cell Carcinoma and Hepatocellular Carcinoma
}

\author{
Dac Hong An Ngo (D) \\ Binh Le Trong (D) \\ Dam Le Dinh ${ }^{2}$ \\ Khanh Le Dinh ${ }^{2}$ \\ Vu Pham Anh ${ }^{2}$ \\ Mao Nguyen $\mathrm{Van}^{3}$ \\ Thao Nguyen Thanh (D) \\ 'Department of Radiology, Hue \\ University of Medicine and Pharmacy, \\ Hue University, Hue, Vietnam; \\ ${ }^{2}$ Department of Surgery, Hue University \\ of Medicine and Pharmacy, Hue \\ University, Hue, Vietnam; ${ }^{3}$ Department \\ of Histology, Embryology, Pathology and \\ Forensic Medicine, Hue University of \\ Medicine and Pharmacy, Hue University, \\ Hue, Vietnam
}

\begin{abstract}
The coexistence of multiple synchronous primary malignancies is uncommon. The coexistence of hepatocellular carcinoma (HCC) and renal cell carcinoma (RCC) is even rarer. We present a case of a 44-year-old male patient with a history of chronic hepatitis $\mathrm{B}$ and a right renal mass treated by radical nephrectomy. At the 2-month follow-up, a new lesion was detected in the left lobe of the liver. Postsurgery histologic evaluation with immunohistochemical study of both lesions confirmed the renal and hepatic lesions to be RCC and HCC, respectively.
\end{abstract}

Keywords: renal cell carcinoma, hepatocellular carcinoma, synchronous cancers, imaging findings, immunohistochemistry

\section{Introduction}

The association of multiple primary tumors is an area of continuing interest from clinical, radiologic and pathologic viewpoints. The coexistence of hepatocellular carcinoma (HCC) and renal cell carcinoma (RCC) is extremely rare. ${ }^{1-3}$ There have been few sporadic cases reported in the English literature. ${ }^{1,2,4-8}$ Herein, we report a case of synchronous HCC and RCC in a male patient with hepatitis B treated with right radical nephrectomy and left hemihepatectomy.

\section{Case Report}

A 44-year-old male patient with a history of chronic hepatitis B presented with general malaise. The patient had no abdominal pain or urinary symptoms. There was no family history of cancer. On admission, vital signs were normal. Physical examination revealed no abdominal tenderness or abnormal masses. Lab tests were within normal limits, including complete blood count, liver function tests, renal function tests and urinalysis. Abdominal ultrasound revealed chronic liver disease and a $4 \times 3 \mathrm{~cm}$ lesion in the right kidney. Contrast-enhanced computed tomography (CECT) of the abdomen (Figure 1) confirmed a right renal mass of $4.9 \times 4.3 \times 3.1 \mathrm{~cm}$, which had arterial enhancement and washout in the portal and delayed phases. Considering the size of the mass, a right radical nephrectomy was performed uneventfully. Postoperative histologic examination confirmed clear-cell RCC (Figure 2).

Two months later, during a follow-up exam, abdominal ultrasound detected a lesion in the left lobe of the liver. The alpha-fetoprotein (AFP) level was 18.24 $\mathrm{ng} / \mathrm{mL}$. Chronic liver disease was diagnosed as class A with a Child-Pugh score of 5 points. Lab tests were within normal limits with no evidence of active hepatitis
Correspondence: Thao Nguyen Thanh Department of Radiology, Hue University of Medicine and Pharmacy, Hue University, Hue, 53000, Vietnam Tel +84906449964

Email ntthao@hueuni.edu.vn 

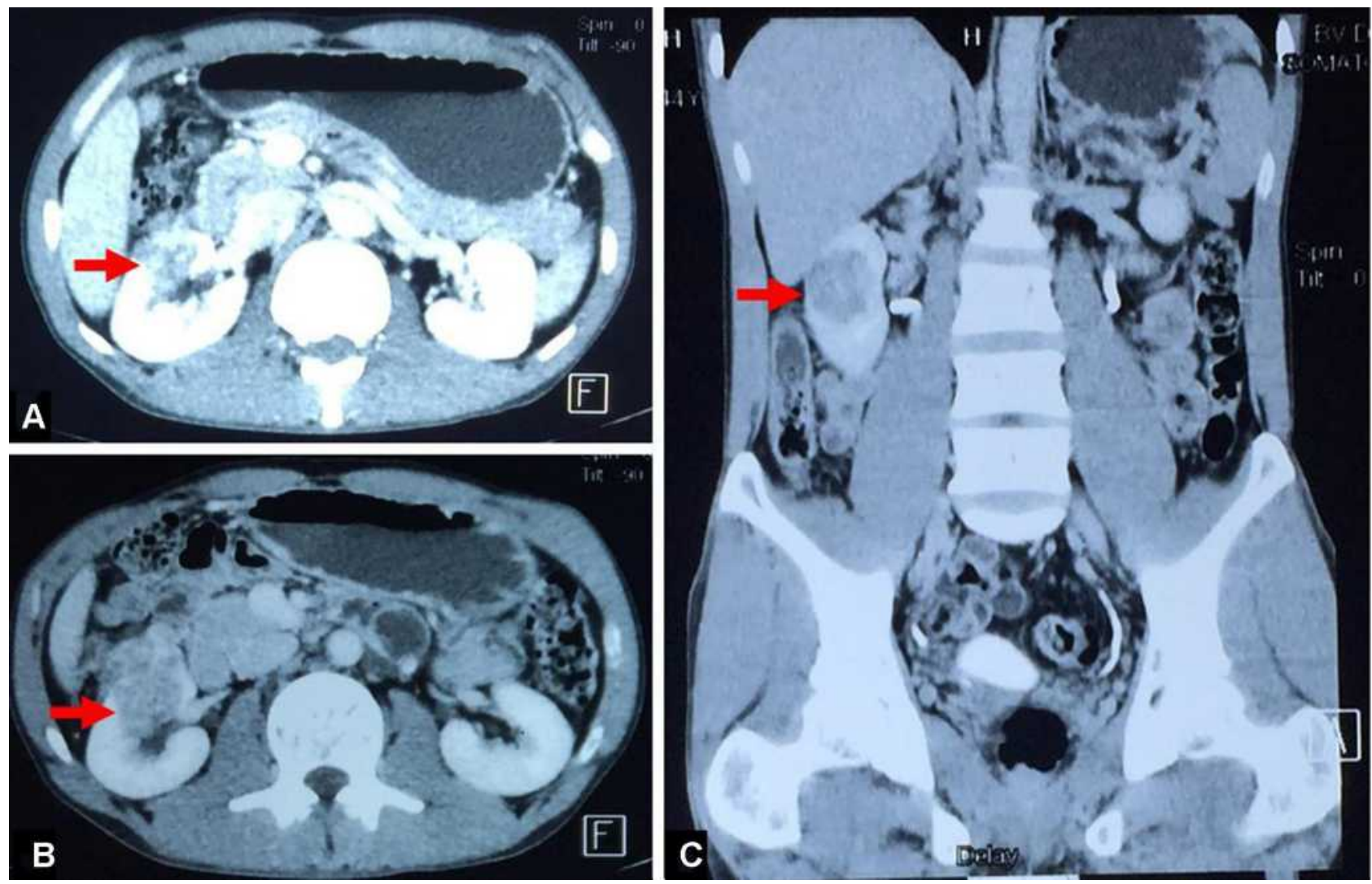

Figure I Abdominal CECT showed a right renal mass (red arrow) with heterogeneous enhancement in the arterial phase (A) and washout in the venous (B) and delayed (C) phases.

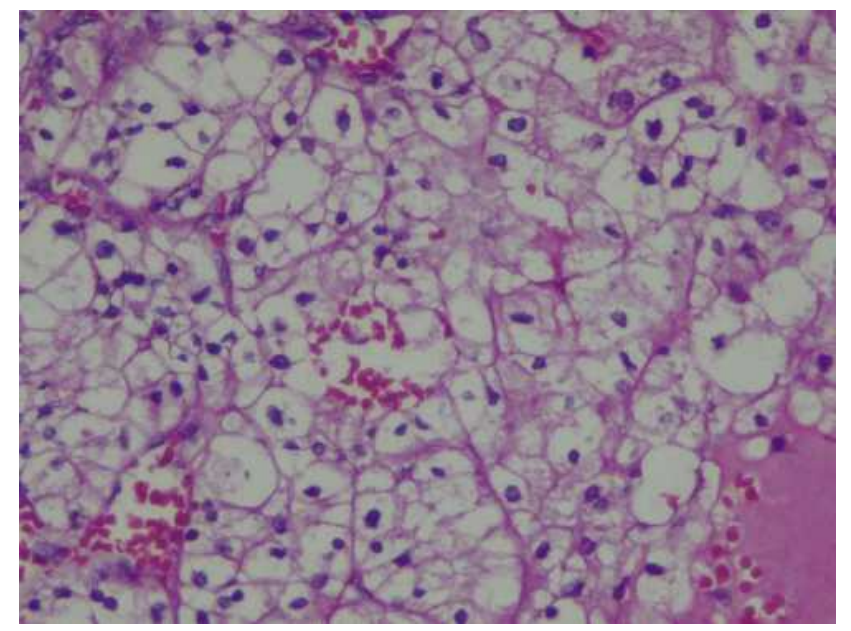

Figure 2 Histological examination of the right renal lesion showed clear-cell RCC.

B infection. An abdominal CECT (Figure 3) and subsequent hepatic magnetic resonance imaging (MRI) with contrast (Figure 4) confirmed a $15 \times 11 \mathrm{~mm}$ hepatic nodule at segment III, which was hyperintense on $\mathrm{T} 1 \mathrm{w}$ and hypointense on $\mathrm{T} 2 \mathrm{w}$ sequences. The lesion was enhanced in the arterial phase and isointense in the liver parenchyma during the portal and delayed phases. According to MRI findings, the differential diagnosis included HCC in a patient with chronic liver disease or metastasis from the previous RCC. A percutaneous biopsy was performed, and histologic evaluation suggested well-differentiated HCC (Figure 5). Considering the size of the tumor and the absence of vascular invasion or distal metastases, a left hemihepatectomy was performed without complications. Immunohistochemistry confirmed the renal and hepatic lesions to be RCC and HCC, respectively (Figures 6 and 7). The patient continued follow-up, and at 10 months after surgery, his clinical status and laboratory tests were within normal limits, and no recurrence or new lesions were found. Institutional Review Board approval was waived due to the nature of the case report to publish the case details. The patient gave consent to publish the case details and any accompanying images.

\section{Discussion}

The association of multiple primary malignancies is a rare condition in which patients simultaneously or successively suffer from one or more malignancies of different 


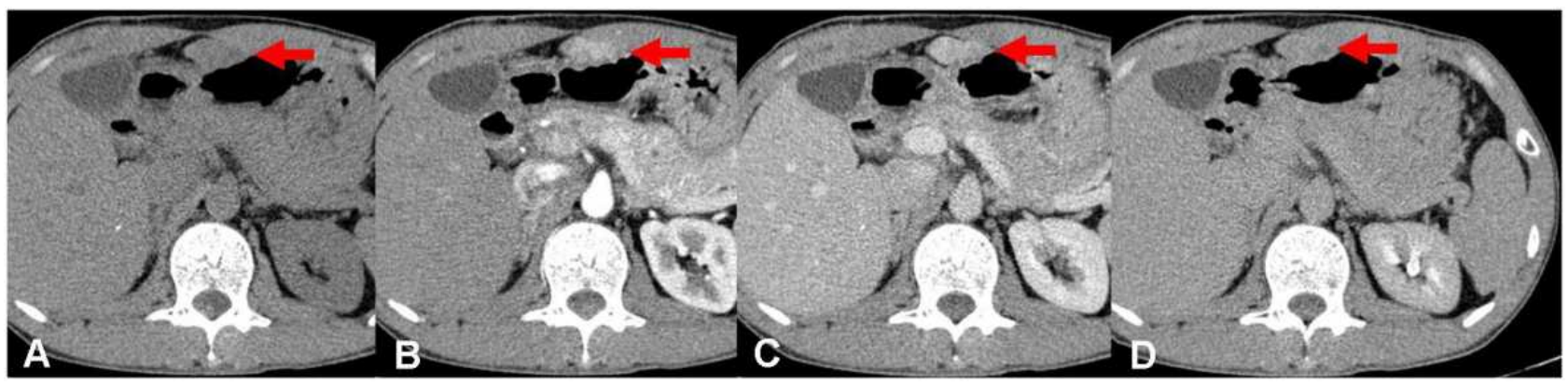

Figure 3 Contrast-enhanced CT of the patient 2 months after right nephrectomy showed a lobulated, hypodense mass (red arrow) in the left lobe of the liver on precontrast scan (A) that was enhanced in the arterial phase (B) with equivocal washout in the portal (C) and delayed phases (D), suggesting HCC or metastasis from RCC.

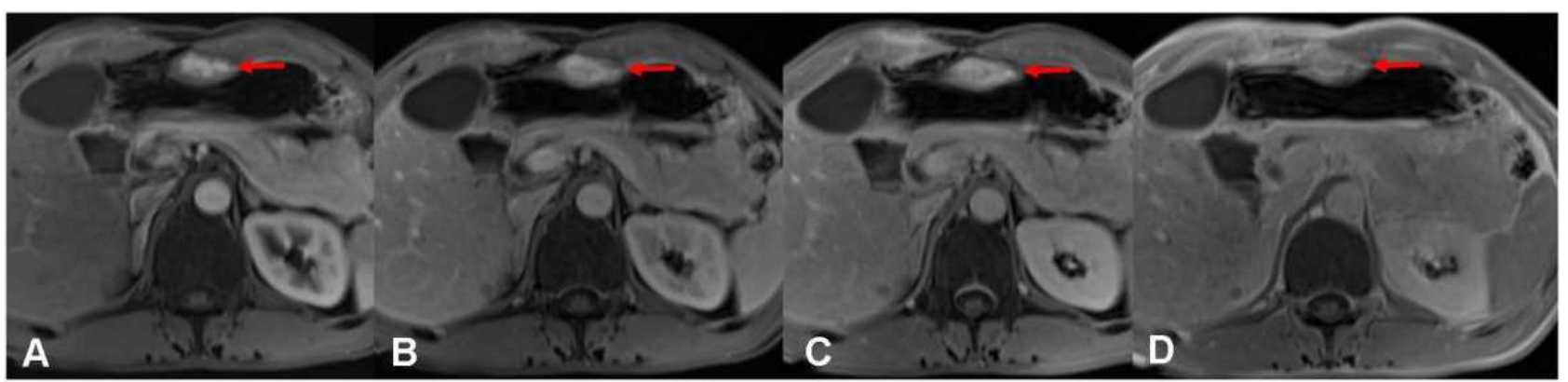

Figure 4 Contrast-enhanced MRI showed a left liver mass (red arrow) with arterial enhancement (A), equivocal washout in the venous (B) and 3-minute delayed phases (C), and a clear capsule in the I5-minute delayed phase (D).

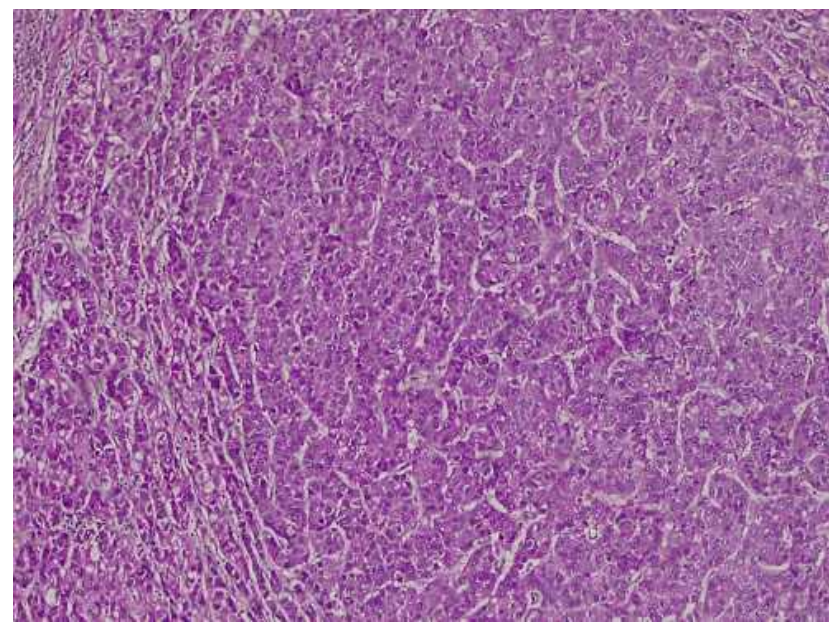

Figure 5 Histology of the liver lesions suggesting HCC.

histological types in multiple organs. ${ }^{9}$ In 1932, Warren and Gates proposed criteria for multiple primary malignancies as: (1) each tumor must present a definite picture of malignancy; (2) must be histologically distinct; and (3) one being a metastasis of another must be excluded. ${ }^{3}$

The incidence of synchronous cancers related to RCC has been reported to be $3.7 \%$, including urological cancers, esophageal carcinoma, colorectal carcinoma, lung cancer, breast cancer, gynecological cancer, sarcoma and non-Hodgkin's lymphoma. ${ }^{2,10}$ The incidence of HCC with extrahepatic primary malignancy (EHPM) has ranged from $2.1 \%$ to $14.5 \%$ in some studies, and the most common site was the gastrointestinal tract, with adenocarcinoma of the colon or gastric carcinoma as the most common tumors. ${ }^{11,12}$ Nzeako et al found one or more EHPMs in 74 of 1349 (5.5\%) patients with HCC. ${ }^{11}$ Of these patients, 65 (4.8\%) had one EHPM, 7 (0.5\%) had two tumors, and 1 each had three and four tumors. HCC with a coexistent EHPM occurred at an older age as compared to that with HCC alone, with a male-to-female ratio of $11: 1 .^{11}$ Patients with $\mathrm{HCC}$ and cirrhosis were 1.8 times more likely to have a coexistent EHPM than noncirrhotic patients with HCC. ${ }^{11}$

The association between HCC and RCC in the same patient is extremely rare. Only 10 of $1349(0.74 \%)$ patients with HCC had a coexistent primary RCC in a North American series. ${ }^{11}$ Another study in Japan found that only 3 RCCs coexisted with a HCC, accounting for $4 \%$ of all synchronous malignancies in the study. ${ }^{12}$

Radical nephrectomy is the treatment of choice for large localized RCCs. ${ }^{13}$ In our case, the mass was larger than $3 \mathrm{~cm}$ with no distant metastases. Thermal ablation was not appropriate, as the lesion was too extensive. As 

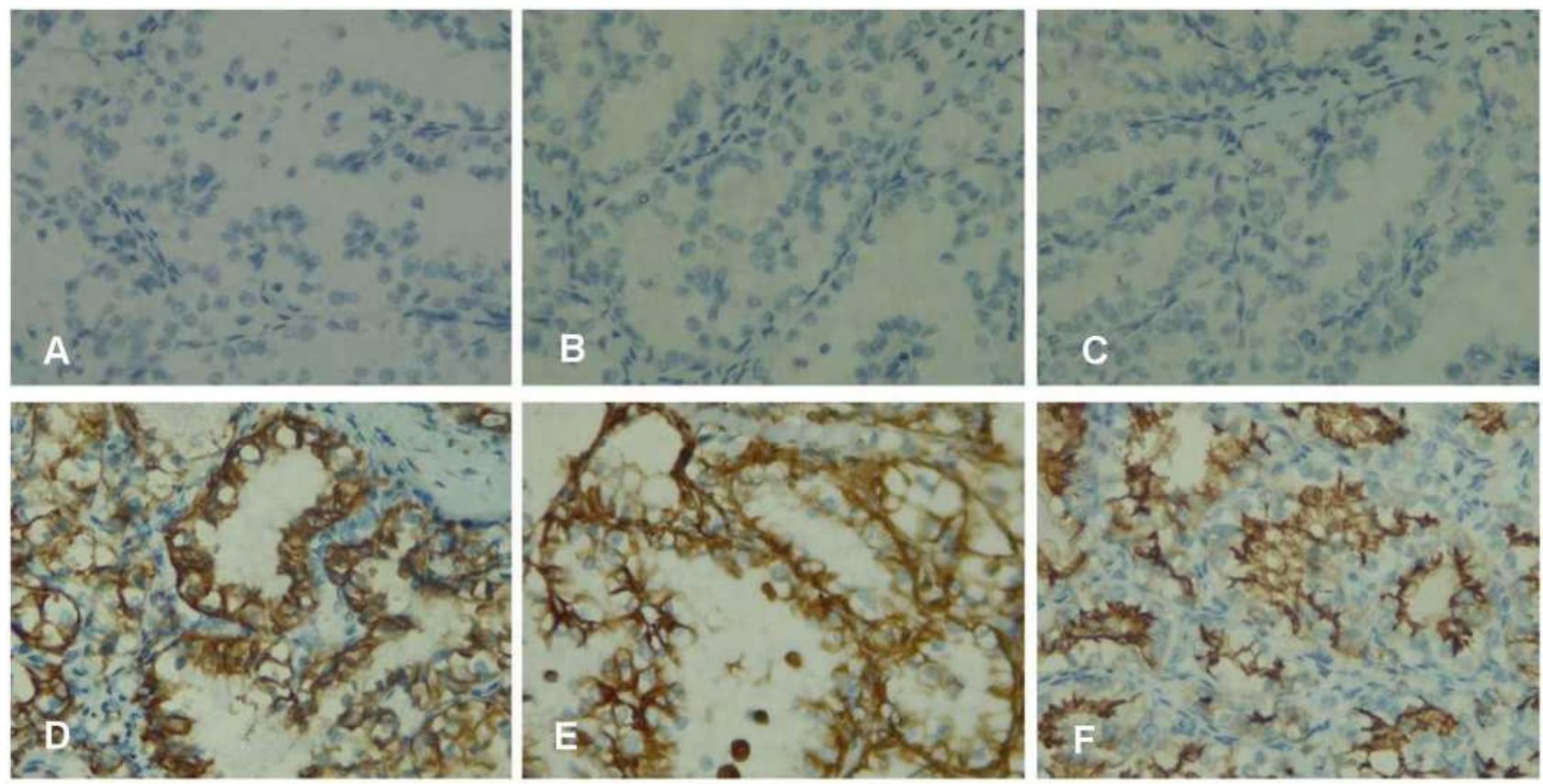

Figure 6 Immunohistochemistry of RCC. (A) HSA (-) (XI00), (B) CK7 (-), (C) CK20 (-), (D) AEI/3 (+), (E) Vimentin (+), (F) CDI0 (+).
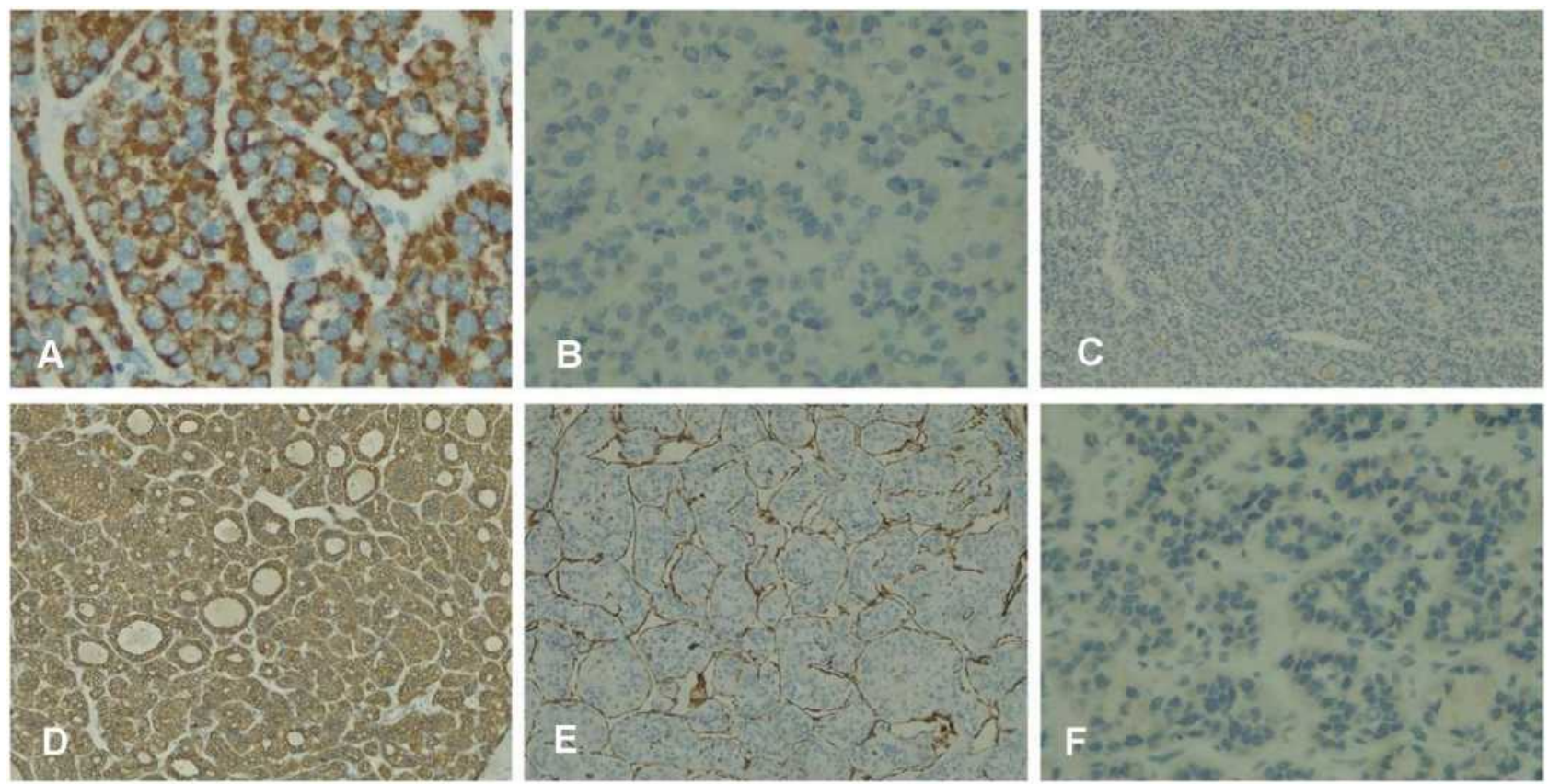

Figure 7 Immunohistochemistry of HCC. (A) HSA (+) (X400), (B) CK7 (-), (C) CK20 (-), (D) AEI/3 (+), (E) Vimentin (-), (F) CDI0 (-).

the tumor developed in the mid-third of the right kidney, partial nephrectomy would not have been feasible. Therefore, a radical nephrectomy was carried out. For liver lesions, prior to intervention, the diagnosis of $\mathrm{HCC}$ is still controversial. Furthermore, in our country, liver transplantation is still expensive, and many cultural reasons have led to a shortage of liver donors. Therefore, transplantation was not considered in our case, and we decided to perform a hemihepatectomy to remove the lesion. Histopathology showed that, in the specimen from the liver, the tumoral cells resembled hepatocytes with trabecular and pseudoglandular patterns. IHC showed HSA, AE1/3 positivity and vimentin, CD10 negativity, which is consistent with $\mathrm{HCC}$, rather than being 
Table I Reported Cases of Synchronous HCC and RCC

\begin{tabular}{|c|c|c|c|c|}
\hline Author & Age/Gender & Hepatitis/Cirrhosis & Lesions & Treatment \\
\hline Shetty $2013^{1}$ & $57 / M$ & N/S & Single HCC $(|2 \times 1| \mathrm{cm})$, clear-cell RCC $(4 \times 3 \mathrm{~cm})$ & $\begin{array}{l}\text { Right hepatectomy and radical } \\
\text { nephrectomy }\end{array}$ \\
\hline Lee $2014^{2}$ & $53 / M$ & Alcoholic cirrhosis & Single HCC $(2.8 \mathrm{~cm})$, clear-cell RCC $(1.9 \mathrm{~cm})$ & Radiofrequency ablation \\
\hline Jekabsone $2014^{6}$ & $58 / M$ & $\mathrm{~N} / \mathrm{S}$ & Single HCC, clear-cell RCC $(3 \times 4 \times 5 \mathrm{~cm})$ & $\begin{array}{l}\text { Hepatic segmentectomy and } \\
\text { radical nephrectomy }\end{array}$ \\
\hline Gang $2015^{14}$ & $72 / M$ & $\begin{array}{l}\text { Hepatitis B and } \\
\text { cirrhosis }\end{array}$ & $\begin{array}{l}\text { Single grade I-II HCC and clear-cell RCC with } \\
\text { renal vein invasion }\end{array}$ & $\begin{array}{l}\text { Radiofrequency ablation and } \\
\text { Sorafenib }\end{array}$ \\
\hline Zhang $2015^{4}$ & $63 / M$ & $\begin{array}{l}\text { Hepatitis B and } \\
\text { cirrhosis }\end{array}$ & $\begin{array}{l}\text { Single HCC }(10 \times 9 \mathrm{~cm}) \text { with diaphragmatic and } \\
\text { peritoneal invasion, clear-cell } R C C 2 \times 2 \mathrm{~cm} \text {. }\end{array}$ & $\begin{array}{l}\text { Right hemihepatectomy and } \\
\text { partial wedge nephrectomy }\end{array}$ \\
\hline Sun $2016^{5}$ & $42 / M$ & Hepatitis B & $\begin{array}{l}\text { Single HCC }(15 \times 8 \mathrm{~cm}) \text { with local invasion, Clear- } \\
\text { cell RCC }(4 \times 4 \mathrm{~cm})\end{array}$ & $\begin{array}{l}\text { Left hemihepatectomy and left } \\
\text { nephrectomy }\end{array}$ \\
\hline Hou $2016^{7}$ & $53 / M$ & No & $\begin{array}{l}\text { Single HCC }(12 \times 9 \mathrm{~cm}) \text { and clear-cell RCC } \\
(4.5 \times 3.5 \mathrm{~cm})\end{array}$ & $\begin{array}{l}\text { Left hemihepatectomy and } \\
\text { right radical nephrectomy }\end{array}$ \\
\hline Current case & $44 / M$ & Hepatitis B & Single HCC $(5 \times 4 \mathrm{~cm})$, clear-cell $R C C(1.5 \times 1 \mathrm{~cm})$ & $\begin{array}{l}\text { Left hemihepatectomy and } \\
\text { radical nephrectomy }\end{array}$ \\
\hline
\end{tabular}

Abbreviations: M, male; N/S, not specified; HCC, hepatocellular carcinoma; RCC, renal cell carcinoma.

metastasized from the kidney or other organs. In the kidney specimen, the tumor consisted of clear cells with massive and pseudoglandular structures. IHC showed vimentin, CD10 positivity and HSA, AE1/3 negativity, so it was a case of RCC that did not metastasize from the liver or other organs.

Reported cases of synchronous HCC and RCC in the English literature are summarized in Table 1. Most cases were treated with surgical resection, and only 2 cases were treated with radiofrequency ablation (RFA). All patients were male, and most of them had hepatitis B with or without cirrhosis.

\section{Conclusion}

With the increase in life expectancy, the risk of developing multiple malignancies also increases. Even synchronous HCC and RCC are rare phenomena. The development of modern radiological modalities, especially MRI, allowed early detection of additional primary malignancies, which enabled prompt management and increased survival rates. Histological and immunohistochemical evaluations should be carried out to ensure the diagnosis of multiple malignancies and rule out metastatic lesions, which are important for indicating radical surgical treatment.

\section{Abbreviations}

MRI, magnetic resonance imaging; $\mathrm{HCC}$, hepatocellular carcinoma; RCC, renal cell carcinoma; CECT, contrastenhanced computed tomography; AFP, alpha-fetoprotein; EHPM, extrahepatic primary malignancy.

\section{Acknowledgment}

This work was supported by Hue University under the Core Research Program, Grant No. NCM.DHH.2020.09.

\section{Disclosure}

The authors report no conflicts of interest in this work.

\section{References}

1. Shetty GS, Bhalla P, Desai SM, Wagle PK, Mehta HS. Synchronous hepatocellular carcinoma with renal cell carcinoma: a case report and review of literature of multiple synchronous primary malignancies. Indian J Surg. 2013;75(Suppl 1):290-292. doi:10.1007/s12262-0120684-4

2. Lee YS, Kim JH, Yoon HY, Choe WH, Kwon SY, Lee CH. A synchronous hepatocellular carcinoma and renal cell carcinoma treated with radio-frequency ablation. Clin Mol Hepatol. 2014;20 (3):306-309. doi:10.3350/cmh.2014.20.3.306

3. Warren S. Multiple primary malignant tumors. A survey of the literature and a statistical study. Am J Cancer. 1932;16:1358-1414.

4. Zhang W, Wang Q, Jiang Y-X, et al. Simultaneous double primary clear cell carcinomas of liver and kidney: a case report and review of literature. Int J Clin Exp Pathol. 2015;8(1):995-999. 
5. Sun -J-J, Yang T-B, Yang Y-H, Liu W-F, Song J-X. Synchronous double primary malignancies of the liver and kidney: a case report. Oncol Lett. 2016;11(3):2057-2060. doi:10.3892/ol.2016.4194

6. Jekabsone S, Bogdanova T, Abolins A, Vanags A, Gardovskis J, Strumfa I. Synchronous renal and hepatocellular carcinomas. Acta Chir Latviensis. 2014;2014:40-42. doi:10.1515/chilat-2015-0008

7. Hou S, Wang L, Qi S. Synchronous hepatocellular carcinoma with renal cell carcinoma: a case report and review of literature. Int J Clin Exp Med. 2017;10(7):11026-11032.

8. Garcia JHP, Coelho GR, Cavalcante FP, et al. Synchronous hepatocellular carcinoma and renal cell carcinoma in a liver transplant recipient: a case report. Transplantation. 2007;84(12):1713. doi:10.1097/01.tp.0000296469.78853.83

9. Jemal A, Bray F, Center MM, Ferlay J, Ward E, Forman D. Global cancer statistics. CA Cancer J Clin. 2011;61(2):69-90. doi:10.3322/ caac. 20107

10. Papalampros AE, Petrou AS, Mantonakis EI, et al. Coexistence of a colon carcinoma with two distinct renal cell carcinomas: a case report. J Med Case Rep. 2011;5:134. doi:10.1186/1752-1947-5-134
11. Nzeako UC, Goodman ZD, Ishak KG. Association of hepatocellular carcinoma in North American patients with extrahepatic primary malignancies. Cancer. 1994;74(10):2765-2771. doi:10.1002/10970142(19941115)74:10<2765::aid-cncr2820741005>3.0.co;2-q

12. Kai K, Miyoshi A, Kitahara K, et al. Analysis of extrahepatic multiple primary malignancies in patients with hepatocellular carcinoma according to viral infection status. Int $J$ Hepatol. 2012;2012:1-6. doi: $10.1155 / 2012 / 495950$

13. Van Poppel H, Becker F, Cadeddu JA, et al. Treatment of localised renal cell carcinoma. Eur Urol. 2011;60(4):662-672. doi:10.1016/j. eururo.2011.06.040

14. Gang G, Hongkai Y, Xu Z. Sorafenib combined with radiofrequency ablation in the treatment of a patient with renal cell carcinoma plus primary hepatocellular carcinoma. $J$ Cancer Res Ther. 2015;11 (4):1026. doi:10.4103/0973-1482.150405

\section{Publish your work in this journal}

Research and Reports in Urology is an international, peer-reviewed, open access journal publishing original research, reports, editorials, reviews and commentaries on all aspects of adult and pediatric urology in the clinic and laboratory including the following topics: Pathology, pathophysiology of urological disease; Investigation and treatment of urological disease; Pharmacology of drugs used for the treatment of urological disease. The manuscript management system is completely online and includes a very quick and fair peer-review system, which is all easy to use. Visit http://www.dovepress.com/ testimonials.php to read real quotes from published authors. 